\title{
Towards the prospection of an optimal thermal response of ZnO surge arrester in HV power system
}

\author{
Abdelhakim Bendakir ${ }^{1}$, Abdelhafid Bayadi², Djalel Dib ${ }^{3}$ \\ ${ }^{1,2}$ Department of Electrical Engineering, Automatic Laboratory of Setif, Ferhat Abbas University, Setif, Algeria \\ ${ }^{3}$ Department of Electrical Engineering, laboratory of Mine LM, Larbi Tébessi University of Tebessa, Algeria
}

\begin{tabular}{l} 
Article Info \\
\hline Article history: \\
Received May 20, 2020 \\
Revised Dec 12, 2020 \\
Accepted Dec 22, 2020 \\
\hline Keywords: \\
COMSOL \\
Electric field \\
Electrical conductivity \\
Electrothermal phenomenon \\
Metal oxide surge arrester \\
Temperature \\
ZnO varistors
\end{tabular}

\begin{abstract}
In order to understand the thermal and electrical properties of surge arrester under standard climatic conditions, it would be useful to evaluate the heating progression in its different elements. These are constituted of heterogeneous materials, which have physical and electrical nonlinear properties along the surge arrester. Temperature predicting solutions for zinc oxide ceramic blocks provide fundamental elements of the electrothermal material characteristics in view of the lifetime estimation. Electrothermal phenomenon analysis of surge arresters is based on empirically-determined parameter models, using finite element method (FEM) simulated on COMSOL Multiphysics software which is a more precise approach compared to the existing models. In this paper, the behavioural model has been developed to study the surge arresters in both cases: the steady state and overvoltage state (lightning). Previous published works validate the first simulation results. This work is therefore extended to consider other operating states, which illustrate the dependence of the type of surge on the amplitudes and durations of electrothermal phenomena.
\end{abstract}

This is an open access article under the $\underline{C C B Y-S A}$ license.

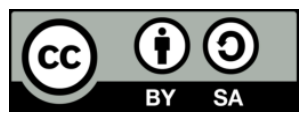

\section{Corresponding Author:}

Djalel Dib

Department of Electrical Engineering, laboratory of Mine LM

Larbi Tébessi University of Tebessa

Route de constantine, 12002, Tebessa, Algeria

Email: dibdjalel@gmail.com

\section{INTRODUCTION}

In the recent decades, surge arresters varistors based on zinc oxide $(\mathrm{ZnO})$ have proved to playing a major role in electrical protection systems as they have remarkable electrical properties such as; low short response time, leakage current suppression, stability and reliability of electric systems, and high-energy absorption capability. This high energy-absorption capacity allows surge arresters to be sized on all networks, from electronics to very high voltage power transmission ( 225 or $400 \mathrm{kV}$ ) which indicates that their energy limits are beyond destruction for the two equipment protection types (overvoltages of Atmospheric originlightning and slow overvoltage switching surge) [1,2].

The varistors are semiconductor devices made of polycrystalline ceramic, with aparticular composition and microstructure [3]. They are variable and are characterized by a high nonlinear resistance to low applied voltage values. A varistor behaves like a high value resistance obeying the law Ohms law but, above a threshold voltage, the device becomes highly conductive with low impedance to the high tensions. When the resistance becomes conductive, it maintains the applied voltage to a maximum value indicated by the protected system, which can withstand it [4]. Indeed, the current-voltage relationship I(V) essentially reflects the quality of varistor from the non-linear and leakage current point of view [5]. 
The varistors are placed in a polymer or porcelain envelope, so that it is not affected by moisture or pollution. These envelopes have traditionally been made of porcelain, but today the trend is towards the use of synthetic insulators [6]. A porcelain surge arresters contains a large amount of dry air or gas (nitrogen), while a synthetic surge arrester does not have all the gas included. This means that the internal conditions against the electric and thermic phenomena must be resolved differently for both designs [7, 8].

In the design of electrical equipment, particularly in protection systems, thermal evaluation is an important factor to increase the lifetime and reliability of this these systems [9]. This paper presents the thermal-electric model developed to study the behavior of $\mathrm{ZnO}$ porcelain surge arrester. The development of this model is relatively complex, as it takes into consideration the non-linearity of the electrical characteristic of ceramics, the non-linearity of thermal phenomena, as well as the coupling of electrical and thermal phenomena during surge arresters' operating. In this context, a procedure for calculating electric conductivity as a function of temperature and electric field is proposed by using an appropriate computer tool. To realize this study, a '2-D' finite element simulation model is developed in a steady state, using COMSOL Multiphysics software, with a detailed consideration of the electrical and thermal parameters, in other words, the relationship between temperature and electric field associated with the voltage distribution on the basis of existing approaches. The results are successfully validated by other work. The use of this simplified model requires the knowledge of natural convection and thermal radiation of these parts of the $\mathrm{ZnO}$ surge arrester.

To extend this work, cases of transient electrical operating conditions are examined to illustrate thermal behaviors under pulsed overvoltages. Finally, the results of last operating case are used to study natural cooling phenomenon. It is shown that, quality simulation results are obtained by finding the correlation between its electric and the thermal parameters.

Under normal operating conditions, $\mathrm{ZnO}$ surge arresters present low leakage current to ground [10]. When a surge arrester is subjected to a transient voltage, the $\mathrm{ZnO}$ elements absorb a large amount of energy and the temperature rises abruptly due to the unequal voltage distribution created by the surface leakage currents [11]. Furthermore, when the applied voltage is below a threshold temperature, the varistors reach a point of balance. From the literature, it is known that, the degree of control has practically no influence on the thermal stability limit of a surge arrester after injections of alternating energy $[12,13]$. Materials temperature is strongly related to power dissipation and temporary overvoltage. Therefore, there is a coupling between electrical behavior active elements ( $\mathrm{ZnO}$ varistors) and the thermal impact of the whole structure.

The heat generated by the losses is in balance with the heat dissipated via the surge arrester towards the ambient air [14]. Whether the ambient temperature or the applied voltage change, the temperature margin may have other values, and consequently its value is not unique. However, if the applied voltage (electric field) exceeds this threshold, the current and the temperature have no balance point, and they will increase continuously until the destruction of the device. The thermal runaway takes place [15].

Protection against thermal runaway requires a prediction of the electrothermal behavior of its elements, that is to say, the estimated temperature margin in which the arrester is stable. The degradation of varistors, caused by the stray capacitances, result in an unequal voltage distribution along the resistance column [16]. This phenomenon reduces the stability zone by moving the upper point towards higher temperatures. Thus, the aging effect creates a new operating point that will evolve until both stability limits are combined, and the arrester can no longer dissipate (destruction) [17].

The majority of the electric models of the MO surge arrester existing in the literature, $[18,19]$ presenting modifications on the equivalent electric circuits, allowed to obtain a set of the electrical parameters according to the approach of each model. The leakage currents flowing through the surge arrester $\mathrm{ZnO}$ block can be divided into resistive and capacitive leakage current [17]. Their density and magnitude are measured for an electric field value close to the nominal operating conditions [20, 21]. Hence, the resistive leakage currents which generate a Joule effect in the $\mathrm{ZnO}$ block, are responsible for the temperature rising, and it is sensitive to the distribution of the voltage in the block $[22,15]$. Several techniques make it possible to calculate the resistive leakage current value, from the total leakage current [23-25]. The resistive current reaches the value of the total current in the moment when the voltage is at its maximum [26].

\section{ELECTRIC PROPERTIES}

The current-voltage characteristic is generally described by (1).

$$
\mathrm{j}=\mathrm{j}_{0}\left(-\frac{\mathrm{q} \emptyset_{\mathrm{b}}}{\mathrm{k}_{\mathrm{B}} \mathrm{T}}\right)\left[1-\exp \left(-\frac{\mathrm{qV_{f }}}{\mathrm{pk}_{\mathrm{B}} \mathrm{T}}\right)\right]
$$

$\mathrm{j}$ is the electronic flux due to the electronic transport through potential barrier and $\mathrm{j}_{0}$ is a constant which can be a function of the temperature and $V_{f}$ is the direct bias potential $[27,28]$. 
The current density increment has two parts:

One is due to the increase of the electric field at constant conductivity as (2).

$$
\sigma(E) d E=\left(\frac{J}{E}\right) d E
$$

The second is due to the increase increment in non-ohmic material, it can be written as (3).

$$
d J=-\frac{J}{E} d E+\beta J d E
$$

Therefore, the semi-empirical equation is:

$$
\mathrm{J}(\mathrm{E})=\sigma_{0} \mathrm{dE} \exp \beta \mathrm{E}
$$

$\sigma_{0}$ : is the electrical conductivity at room temperature, it calculate in the first ohmic region using the ohmic relation [2].

The electric field and the temperature are interrelated. Furthermore, nonlinear factor is proportional to the voltage barrier height level [29]. At low electrical fields $(\beta E<1)$ the Ohm's law will be:

$$
J=\sigma_{0} E \text {. }
$$

At high fields, $\sigma(E)=\sigma_{0} / E$, the conductivity increases with the electric field exponentially:

$$
\sigma(\mathrm{E})=\sigma_{0} \exp \beta \mathrm{E}
$$

The characteristic $V(I)$ must represent the non-linear conductivity, and also temperature effect in the electric current low zone. $V(I)$ is simulated by:

$$
\begin{aligned}
& \mathrm{J}(\mathrm{E}, \mathrm{T})=\mathrm{J}_{0} \exp (\mathrm{N} . \mathrm{T}) \exp (B . E) A / m^{2} \\
& \sigma(\mathrm{E}, \mathrm{T})=\sigma_{0} \exp (\mathrm{N} . \mathrm{T}) \exp (B . E) S / m
\end{aligned}
$$

where,

$J_{0}, B, N, \sigma_{0} \quad$ : constant.

$\mathrm{E} \quad$ : Electric field at the terminals of the varistor $[\mathrm{V} / \mathrm{m}]$.

$\mathrm{T} \quad$ : Temperature in $\left[\mathrm{K}^{0}\right]$.

J : The current density $\left[\mathrm{A} / \mathrm{m}^{2}\right]$.

As shown in (7) and (8), which are used to represent the characteristic $V(I)$, have the advantage of including both temperature effect and different electrical and physical quantities of materials. In order to solve these equations, an algorithm is proposed to find the curve of electrical conductivity according to temperature and electric field as shown in Figure 1.

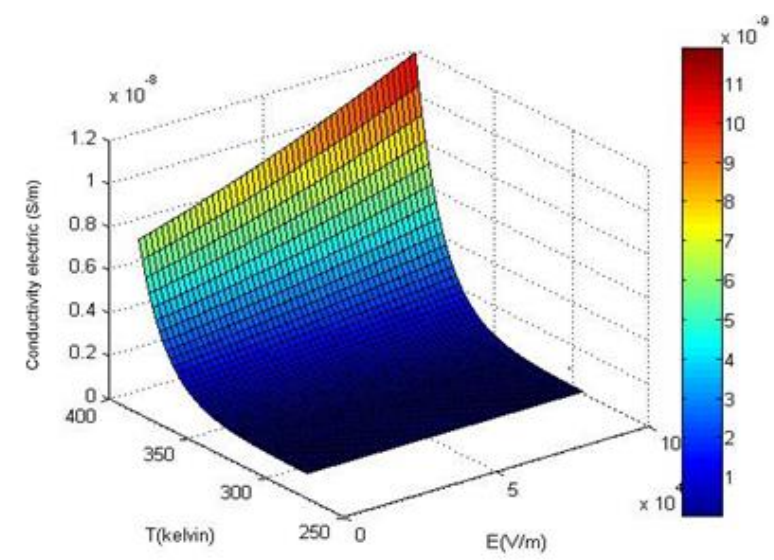

Figure 1. Electric conductivity as a function of temperature and electric field 
Figure 1 demonstrates that the electrical conductivity of zinc oxide in the low current zone increases with the increase of electric field and temperature.The distribution of the temperature inside surge arrester influences the electric fields. Likewise, the distribution of the temperature between the individual elements of $\mathrm{ZnO}$, both in normal operation and transient overvoltages, influences the voltage profile along the arrester. Therefore, a very complicated analysis is needed in the design of surge arresters. This analysis should cover mutual coupling between the thermal and electrical phenomena [30].

The heat diffusion equation takes the form [31]:

$$
\mathrm{D}(\mathrm{T})\left(\frac{\partial^{2} \mathrm{~T}^{\prime}}{\partial \mathrm{r}^{2}}+\frac{1}{\mathrm{r}} \frac{\partial \mathrm{T}^{\prime}}{\partial \mathrm{r}}+\frac{\mathrm{Q}(\mathrm{r})}{\mathrm{k}_{0}}\right)=\frac{\partial \mathrm{T}^{\prime}}{\partial \mathrm{t}},
$$

where,

$\mathrm{D}(\mathrm{T})=\frac{\mathrm{k}(\mathrm{T})}{\mathrm{c}_{\mathrm{p}}}$, is the diffusivity.

Since the thermal conductivity $\mathrm{k}(\mathrm{T})$ depends strongly on temperature [31], the scaled temperature T' is used,

$$
\mathrm{T}^{\prime}(\mathrm{T})=\frac{1}{\mathrm{k}_{0}} \int_{\mathrm{T}_{0}}^{\mathrm{T}} \mathrm{k}(\mathrm{T})
$$

The temperature T' and the input heat Q presented in (9) depend on $r$ (the radial distance from the disk center) and on $\mathrm{t}$ (time). The heat dissipates only radially by convection to air over the sidewall, since disks mounted in a surge arrester do not have significant axial heat conduction to neighboring disks [13].

\subsection{The corresponding boundary condition}

Electrothermal simulation requires knowledge of physical materials parameters. Comsol multiphysics has a database containing a set of numerical values for the different physical constants characterizing the materials. The values are taken directly from the literature [11].

$$
\left.\frac{\partial \mathrm{T}^{\prime}}{\partial \mathrm{r}}\right|_{\mathrm{r}=\mathrm{R}}=-\chi\left[\mathrm{T}\left(\mathrm{T}^{\prime}(\mathrm{R}, \mathrm{t})\right)-\mathrm{T}_{\mathrm{A}}\right]^{5 / 4},
$$

The heat conduction equation in cylindrical co-ordinates for axial symmetry problems is:

$$
\frac{\mathrm{k}}{\mathrm{r}} \frac{\partial \mathrm{T}}{\partial \mathrm{r}}\left(\mathrm{r} \frac{\partial \mathrm{T}}{\partial \mathrm{r}}\right)+\frac{\partial}{\partial \mathrm{z}}\left(\mathrm{k} \frac{\partial \mathrm{T}}{\partial \mathrm{z}}\right)+\mathrm{q}=\mathrm{C}_{\mathrm{p}} \rho \frac{\partial \mathrm{T}}{\partial \mathrm{t}}, r>0, t>0
$$

\section{ELECTROTHERMAL MODELING OF ZnO SURGE ARRESTER}

The general configuration as depicted in Figure 2 is a $2 \mathrm{D}$ diagram of $\mathrm{ZnO}$ surge arrester; it represents the main components and their dimensions. In this device, three types of material regions are present:

- $\quad$ The $\mathrm{ZnO}$ varistors column which has electrical characteristics $\mu_{\mathrm{r}}$ and $\varepsilon_{\mathrm{r}}$

- The covers at each end, and the joints among two adjacent varistors is made in aluminum with characteristics $\sigma, \varepsilon_{\mathrm{a}}$, and $\mu_{\mathrm{a}}$

- The housing insulation material is made of porcelain $\sigma_{\mathrm{e}}, \varepsilon_{\mathrm{e}}$, and $\mu_{\mathrm{e}}$.

The entire geometry of the model is surrounded by air. The electrothermal surge arrester model is developed in finite element method (FEM). It consists in coupling a thermal and electrical phenomenon. The COMSOL Multiphysics software works on heat flow, and electrical potential, resulting from an imposed voltage that passes through a resistive material. It solves the equations system arising from the electric charge conservation, and the thermal energy balance to calculate the temperature.

The equation of continuity: $-\nabla \cdot(\sigma \nabla V)=0$ 


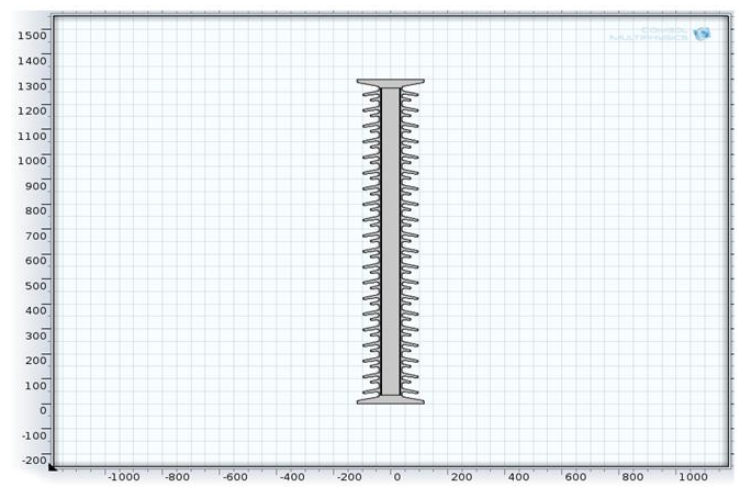

Figure 2. Definition of geometry in COMSOL multiphysics

\subsection{Electrical properties of the envelope}

AR. Rahisham et al. [25] proposed an FEM modeling of the surge arrester envelope (non-conductive regions). The approximation represented by a mathematical expression:

$$
\nabla \times \mathrm{E}=-\frac{\partial \mathrm{B}}{\partial \mathrm{t}}=0
$$

SinceE $=-\nabla \mathrm{V}$, and by applying the divergence to the Maxwell-Amperes law:

$$
\nabla . \nabla \times H=\nabla \cdot\left[\mathrm{J}+\frac{\partial \mathrm{D}}{\partial \mathrm{t}}\right]
$$

where, the current density: $J=\sigma . E$; and the displacement vector: $\mathrm{D}=\varepsilon_{0} \varepsilon_{\mathrm{r}} \mathrm{E}$

The potential distributions and the electric field are calculated in time domain as:

$$
-\nabla \cdot \frac{\partial}{\partial t}\left(\varepsilon_{0} \varepsilon_{\mathrm{r}} \nabla \cdot \mathrm{V}\right)-\nabla \cdot(\sigma \nabla \cdot \mathrm{V})=0
$$

In this expression, $\mathrm{V}$ is the potential, $\sigma$ is the electrical conductivity, $\varepsilon_{0}$ is the permittivity of the vacuum, and $\varepsilon_{\mathrm{r}}$ is the relative permittivity of the material.

\subsection{Heat transfer}

$$
Q=\rho \cdot c p \frac{\partial T}{\partial t}-\nabla \cdot(k \nabla T)
$$

The link between the two equations is the joule effect, defined by:

$$
\mathrm{Q}=\mathrm{J} \cdot \mathrm{E}=\sigma \mathrm{E}^{2}
$$

where, Q: is the heat flux $\left(\mathrm{W} / \mathrm{m}^{3}\right)$.

\subsection{Model validation}

The developed model is confronted to two different time constants. The thermal constant time is between $1 \mathrm{~h}$ and $4 \mathrm{~h}$, while the constant time for electrical phenomenon is in the order of a few milliseconds. To calculate the thermal phenomena, the time step retained is about several dozen seconds. It should be noted that some adjustments are needed in the coupling of thermal and electrical phenomenon to observe their influences in $\mathrm{ZnO}$ varistor [32]. Moreover, under these conditions, the electrical study is assimilated to a continuous regime and its model contains only non-linear resistances. This representation is justified by the fact that electrical study has a dominant resistive behavior, which is mainly used to indicate high temperatures. SuBong Lee et al. [15] applied a voltage of $18 \mathrm{kV}$ with a normal frequency of $50 \mathrm{~Hz}$ on surge arrester Figure 3(a) for four hours. The obtained results are illustrated in Figure 3(a), and Figure 4(a). Figure 3(b) represents a simulation of the experimental work carried out by these researchers under the same boundary conditions:

- $\quad$ The applied voltage $18 \mathrm{kV}$,

- The ambient temperature $20{ }^{\circ} \mathrm{C}$.

- $\quad$ Heat convection coefficient $h=60\left[\mathrm{~W} / \mathrm{m}^{2} . K\right]$.

Towards the prospection of an optimal thermal response of $\mathrm{ZnO}$ surge arrester ... (Abdelhakim Bendakir) 


\section{RESULTS AND DISCUSSION}

The simulation results are shown in Figure 3(a) and Figure 4(a). In Figure 3(a), it can be observed that, the temperature distribution is similar to the results obtained experimentally in Figure 3(b). It has been revealed that, the temperature value in the electrodes is lower than in the middle. Accordingly, its maximum value is in the middle of the surge arrester (it reaches $50{ }^{\circ} \mathrm{C}$ experimentally and $48{ }^{\circ} \mathrm{C}$ by simulation).

In Figure 4(a), the thermal profile along the surge arrester is represented at different times, obtained by simulation. An increase of temperature is observed. From 80 minutes, the temperature difference between two successive periods of 20 minutes decreases. The temperature distribution of this simulation Figure 4(a) is close to the results obtained experimentally Figure 4(b) [15]. Furthermore, the general appearance is present in simulation results, although, the order of magnitudes is not directly compared, because the authors [20] do not indicate the electrical parameters, as well as relative permittivity as well as and non-linear conductivity of the varistors. Note, however, that the order of magnitude is well respected.

This set of results Figures 3 to 4(a), shows clearly a concordance between the results obtained from the two modelings which are different in the theoretical point of view. The Comsol Multiphysics software makes it possible to perform calculations, by solving the integral temperature equations, by the finite element method, taking into account the nonlinear conductivity of $\mathrm{ZnO}$. This calculation is rigorous and carried out without any simplifying assumption.

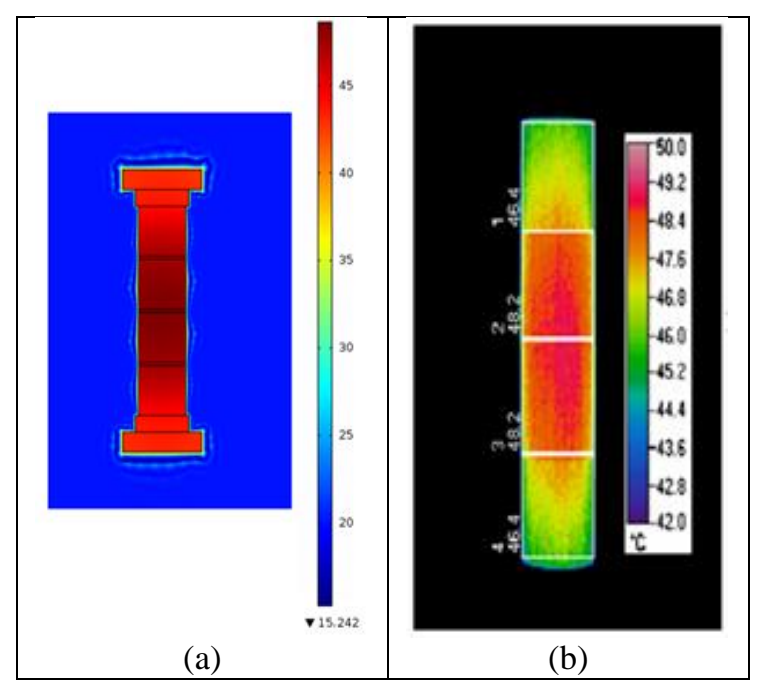

Figure 3. Temperature distribution on the surge arrester after 4 hours, (a) simulation (b) experimental [20]

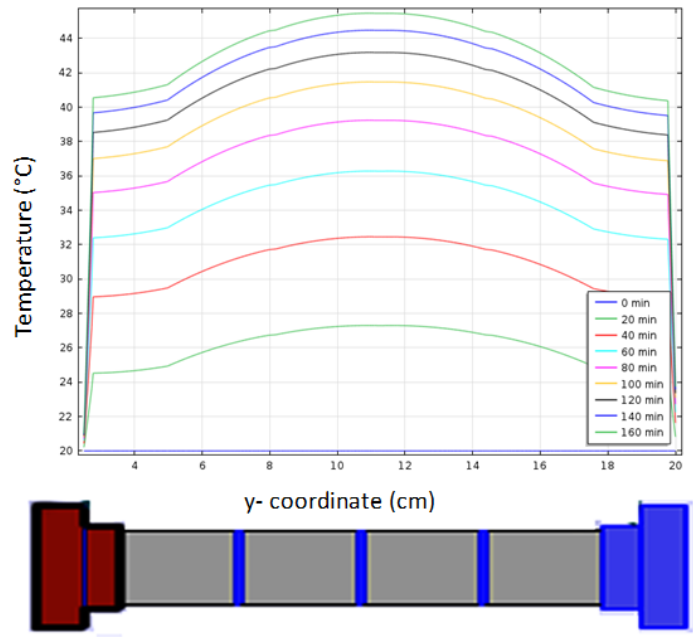

(a)

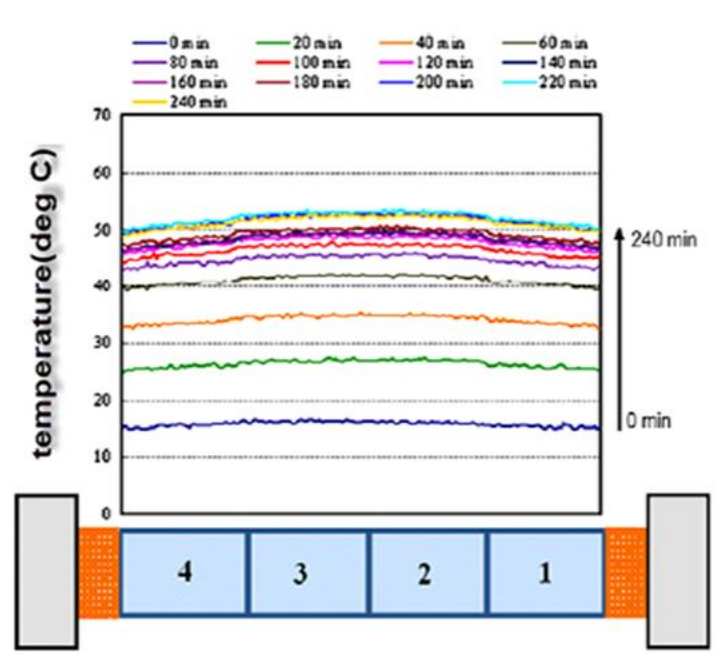

(b)

Figure 4. Thermal profile of a surge arrester with time, (a) simulation (b) experimental [20] 


\section{APPLICATION OF THE MODEL TO A 110 KV SURGE ARRESTER}

\subsection{Under continuos operating}

Under continuous operating conditions, the applied voltage is $110 \mathrm{kV}$ to top electrode, at room temperature of $20^{\circ} \mathrm{C}$ and the simulation time is $2 \mathrm{~h} 15 \mathrm{~min}$. The obtained results are shown in Figures 5. From Figure 5, the temperature value is maximum in the middle of the surge varistor and minimal at the electrodes. Thus, the surge arrester temperature varies between $20{ }^{\circ} \mathrm{C}$ and $27^{\circ} \mathrm{C}$, and it remains stable when the applied voltage is about $110 \mathrm{kV}$. The power loss created by the leakage current is equal to the heat emitted into ambient air.

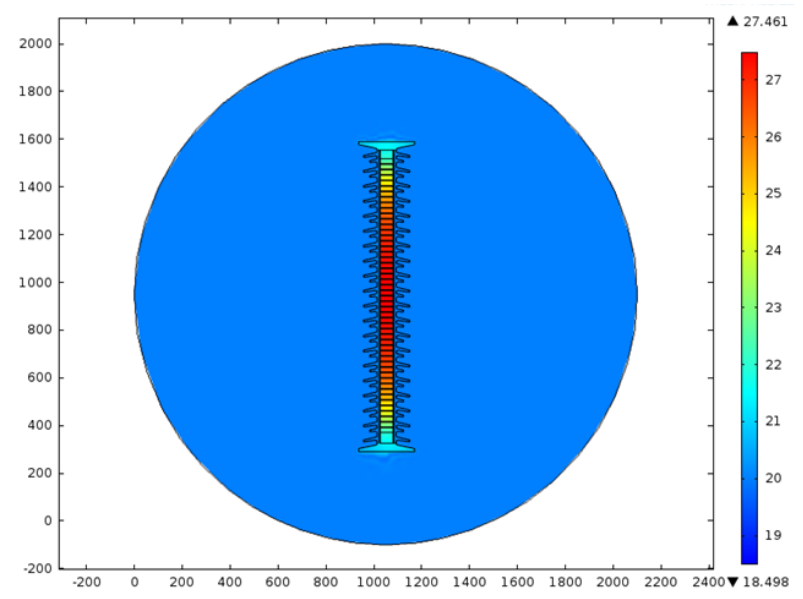

Figure 5. Temperature distribution after $2 \mathrm{~h} 15$ minutes

Figure 6 shows thermal profile along the surge arrester under an applied permanent voltage of $110 \mathrm{kV}$ for 2 hours and 15 minutes. The distribution of non-uniform heat in the varistors is observed. The $\mathrm{ZnO}$ varistor near the aluminum electrode is characterized by a lower temperature, because metallic electrodes (Aluminum) that promote the release heat on both ends. In addition, the general form of porcelain insulators causes a temperature increase to the maximum value in the middle of the surge arrester, due to the small amount of released heat released. To determine temperature variation as a function of time in the surge arrester, several points are chosen in different heights. The reference height is $\mathrm{h}=0 \mathrm{~cm}$, at the low voltage electrode. The simulation results are shown in Figure 7, which illustrates the influence of height on temperature as a function of time. It is obvious that the temperature in interval [0,100 min] varies proportionally with time. However, from 100 minutes, the temperature value remains constant with time increase, due to the equilibrium between generated and dissipated power. The study of thermal balance of a varistor must be carried out in all its operating regimes, because the danger of thermal runaway may occur at any time [2].

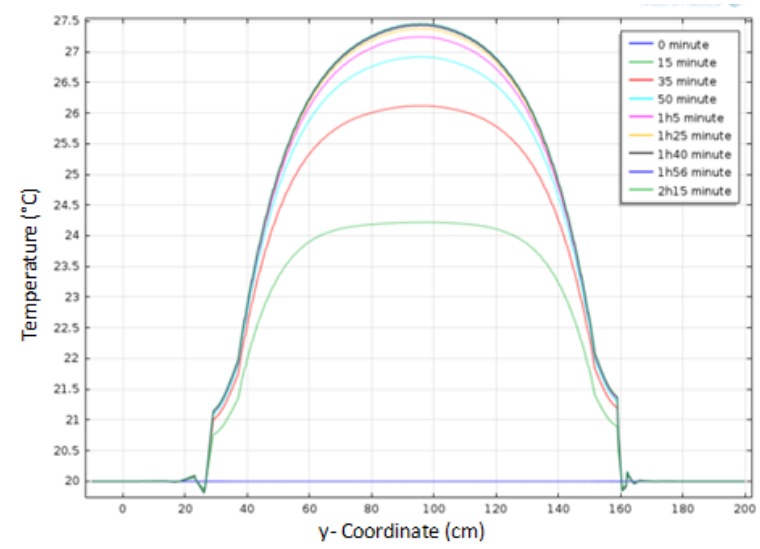

Figure 6. Temperature profile along the arrester

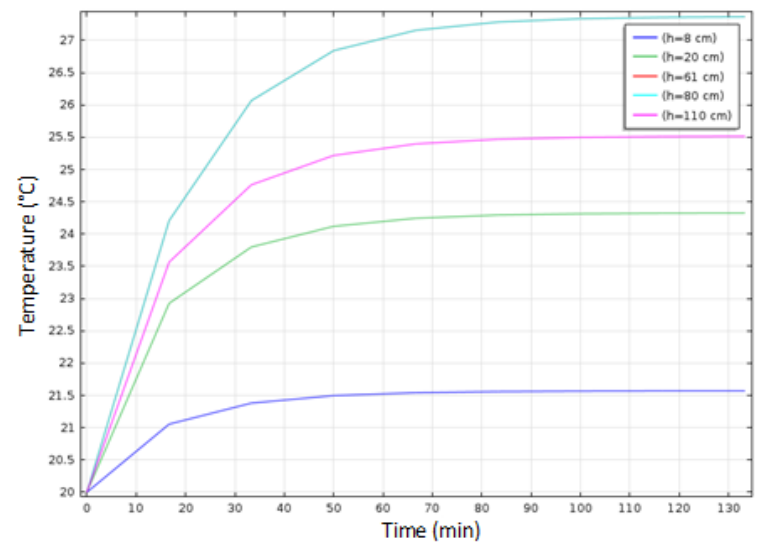

Figure 7. Thermal profile along the surge arrester 


\subsection{Transient analysis}

Most of the time, surge arresters operating operate in a non-continuous mode. It is important to follow the thermal behavior in a transient mode (lightning, switching). A bi-exponential lightning voltage surge of $1.2 / 50 \mu$ is applied; the waveform is given by (19):

$$
V(t)=\eta \frac{a V_{0}}{\sqrt{a^{2}-1}}\left[\exp \left(-\frac{\left(a-\sqrt{a^{2}-1}\right) t}{b}\right)-\exp \left(-\frac{\left(a+\sqrt{a^{2}-1}\right) t}{b}\right)\right]
$$

where, $a=6.9, b=4.9 \mu s, \eta=0.98$, and $V 0=110 \mathrm{kV}$.

The simulation lasts for 60 minutes; the result of the temperature distribution on the surge arrester is shown in Figure 8 and Figure 9. At transient regime, the $\mathrm{ZnO}$ blocks' temperature increases to $81{ }^{\circ} \mathrm{C}$ after 60 minutes. Figure 9 shows the thermal profile as a function of time. Temperature profile, along the symmetry axis of the arrester, at the point of the medium under transient conditions, reaches $75{ }^{\circ} \mathrm{C}$. When the temperature of the $\mathrm{ZnO}$ blocks exceeds the limit, it causes a thermal imbalance between the production of heat and the released one which can lead to failures or thermal runaway. It is concluded that the degradation phenomena and the thermal runaway of the $\mathrm{ZnO}$ surge arrester block are directly related to the heat lossless, which determines the generation and temperature dissipation processes.

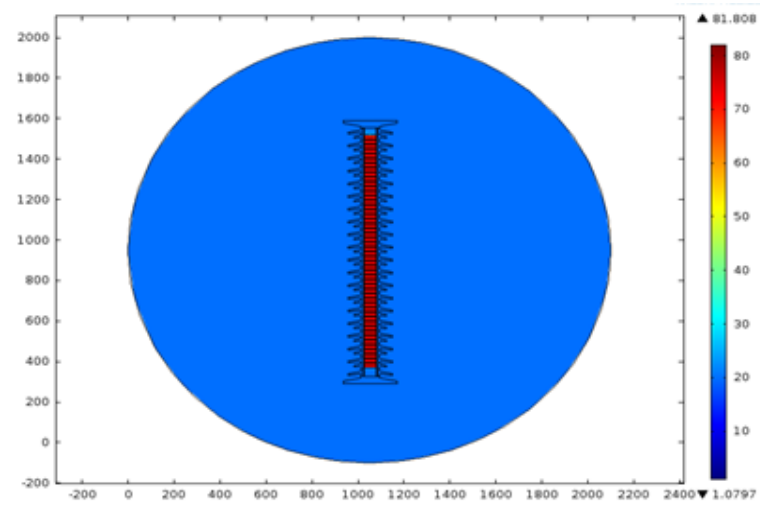

Figure 8. Temperature distribution on surge arrester after 60 minute

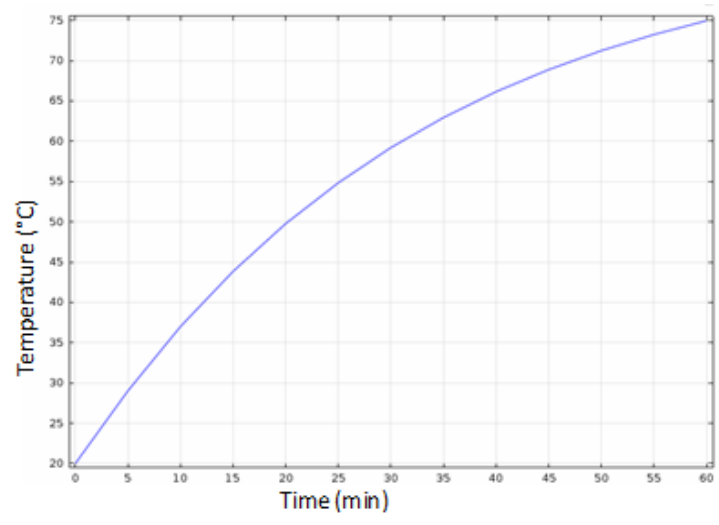

Figure 9. Thermal profile as a function of time (middle point)

\subsection{Cooling under voltage}

The transient regime results are exploited as initial state in the cooling study under voltage of steady state for 3 hours. The result of the simulation is shown in the Figure 10. The characteristics of the thermal stability of this surge arrester can be determined from the amount of heat released directly by the surge arrester. The values obtained in the median part of $\mathrm{ZnO}$ varistors at ambient temperature of $20{ }^{\circ} \mathrm{C}$, are illustrated in Figure 10. The cooling rate is very low (it takes $130 \mathrm{~min}$ ) due to the low thermal conductivity. In addition, the heat can be dissipated to the housing surface with a low temperature gradient [32].

The distribution of heat as a function of time is given by:

$$
\mathrm{T}(\mathrm{t})=\left(\mathrm{T}_{0}-\mathrm{T}_{\mathrm{a}}\right) \exp (-\mathrm{t} / \tau)+\mathrm{T}_{\mathrm{a}}
$$

where,

$\tau \quad$ : Constant of time.

$\mathrm{T}_{\mathrm{a}}$ : Ambient temperature $20^{\circ} \mathrm{C}$.

$\mathrm{t} \quad$ : Heat release time

By fixing $\mathrm{t}=\tau$ and entering the previous equation, the temperature value obtains $\mathrm{T}=40{ }^{\circ} \mathrm{C}$, this value will be projected on curve 18 to find $\tau=68 \mathrm{~min}$. During the first minutes of cooling, extreme ceramics temperature decreases very rapidly due to the heat dissipation by conduction towards the covers, and the large heat capacity of these covers. The central part cools in a uniform way, because the covers influence is minimal, for the order of the initial heating magnitude. In that case, most of the central part heat is evacuated by radiation, convection and conduction between the $\mathrm{ZnO}$ column and the porcelain. 


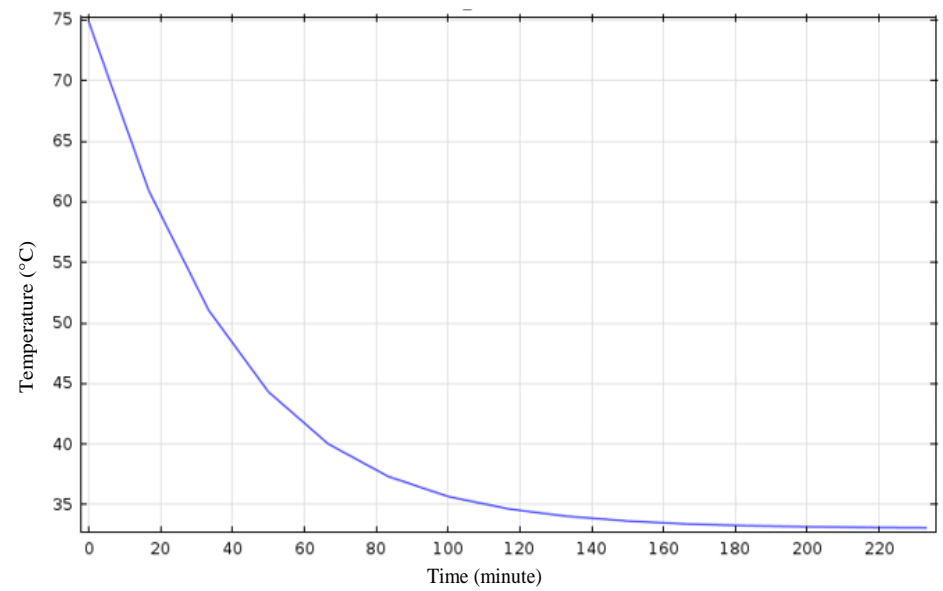

Figure 10. Variation of the thermal profil over time (middle point)

\section{CONCLUSION}

The surge arrester operations are simulated by an electrothermal study, in order to predict its behavior under thermal factors' influence. This is one of the vital characteristics of surge arresters, that must ensure the proper power electrical network operating. The work covered in this paper consists essentially of two main parts: In the first part, the electrical and thermal properties of the different materials, used in the proposed model, were extracted from the COMSOL multiphysics software library. In addition, an algorithm is developed to implement the non-linear characteristics (electrical conductivity and thermal conductivity, thermal capacity) in this software. In the steady state after a few hours, a temperature skew distribution with higher temperatures in the middle area of surge arrester will then also occur.

From the obtained simulation results, it could be shown that the operating regime has a major influence on the average and maximum temperatures of the surge arrester, ie, an influence on the determined thermal stability limits. However, the temperature pattern along the arrester (maximum values in the medium and lower in the limits) is similar, and could be observed, whatever the injection regime is. This result confirms previous studies from the literature.

\section{REFERENCES}

[1] Christodoulou C. A., Vita V., Perantzakis G., Ekonomou L., Milushev G., "Adjusting the parameters of metal oxide gapless surge arresters' equivalent circuits using the harmony search method," Energies, vol. 10, no. 12, p. $2168,2017$.

[2] Flaviu Mihai Frigura-Iliasa, Sorin Musuroi, Ciprian Sorandaru, Doru Vatau, "Case Study about the Energy Absorption Capacity of Metal Oxide Varistors with Thermal Coupling," Energies, vol. 12, no. 3, p. 536, 2019.

[3] S. A. Amin, "Structural and Electrical Properties of ZnO Varistor with Different Particle Size for Initial Oxides Materials," Nanoscale Reports, vol. 2, no. 2, pp. 20-31, 2019.

[4] Christodoulou C. A., Ekonomou L., Mitropoulou A. D., Vita V., Stathopulos I. A., "Surge arresters' circuit models review and their application to a Hellenic $150 \mathrm{kV}$ transmission line," Simulation Modelling Practice and Theory, vol. 18 , no. 6, pp. 836-849, 2010.

[5] Nurul A. A. Latiff, Hazlee A. Illias, I. D., Ab H. A. Bakar, Sameh Z. A. Dabbak, "Measurement and Modelling of Leakage Current Behaviour in ZnO Surge Arresters under Various Applied Voltage Amplitudes and Pollution Conditions," Energies, vol. 11, no. 4, p. 875, 2018.

[6] Anderson Janotti, and Chris G. Van de Walle, "Fundamentals of zinc oxide as a semiconductor," Reports on Progress in Physics, vol. 72, no. 12, 2009.

[7] V. Vita, A. D. Mitropoulou, L. Ekonomou, S. Panetsos, and I. A. Stathopulos, "Comparision of metal oxide surge arresters circuit model and implementation on high voltage transmission lines of the Hellenic network," IET Generation, Transmission \& Distribution, vol. 4, no. 7, pp. 846-853, 2010.

[8] Arthur F. Andrade, Edson G. Costa, Josué M. B. Fernandes, Helem M. M. Alves, Cícero R. C. Amorim Filho "Thermal Behaviour Analysis in a Porcelain-Housed ZnO Surge Arrester by Computer Simulations and Thermography," High Voltage, vol. 4, no. 3, pp. 173-177, 2019.

[9] F. M. Frigura-Iliasa, D. Vatau, L. N. Mihet-Popa, "Heat Dissipation Improvement for ZnO Based Varistors," Proceedings of 14th International Conference on Harmonics and Quality of Power - ICHQP 2010, Bergamo, 2010, pp. 1-6.

[10] Paulo R. Bueno, Jose A. Varela, Elson Longo, "SnO2, ZnO and related polycrystalline compound semiconductors: An overview and review on the voltage-dependent resistance (non-ohmic) feature," Journal of the European Ceramic Society, vol. 28, no. 3, pp. 505-529, 2008. 
[11] Späck-Leigsnering, Y., Gjonaj, E., De Gersem, H., Weiland, T., Gießel, M., Hinrichsen, V., "Electro-Quasistatic Thermal Modeling and Simulation of Station Class Surge Arresters," IEEE Transactions on Magnetics, vol. 52, no. 3, pp. 1-4, 2016.

[12] Costa, E. G., Barros, R. M. R., Alves, H. M. M., Bastos, M. A., "Thermal behavior analysis of ZnO polymeric surge arrester using the finite elements method," 2014 ICHVE International Conference on High Voltage Engineering and Application, Poznan, 2014, pp. 1-4.

[13] Hinrichsen, V., Gießel, M., Tuczek, M. N., "Thermal Stability of HV and UHV Arresters with Reduced Grading Systems," In: INMR World Congress on Insulators, Arresters, Bushings \& Cable Accessories, 2015.

[14] Gießel, M., Hinrichsen, V., Göhler, R., Späck Leigsnering, Y., Gjonaj, E., De Gersem, H., "ElectroThermally Coupled Finite-Element Simulations of High Voltage Station Arresters with and without Grading," INMR World Congress, 2017.

[15] Su-Bong Lee, Seung-Ju Lee E. T. Bok-Hee Lee., "Analysis of thermal and electrical properties of ZnO arrester block," Current Applied Physics, vol. 10, no. 1, pp. 176-180, 2010.

[16] Christodoulou C. A., Vita V., Mladenov V., Ekonomou L., "On the computation of the voltage distribution along the non-linear resistor of gapless metal oxide surge arresters," Energies, vol. 11, no. 11, p. 3046, 2018.

[17] Jiazheng Lu, Pengkang Xie, I. D., Zhen Fang and Jianping Hu, "Electro-Thermal Modeling of Metal-Oxide Arrester under Power Frequency Applied Voltages," Energies, vol. 11, no. 6, p. 1610, 2018.

[18] Christodoulou C. A., Vita V., Maris T. I., "On the optimal placement of surge arresters for the efficient protection of medium voltage distribution networks against atmospheric overvoltages," 2019 54th International Universities Power Engineering Conference (UPEC), Bucharest, Romania, 2019, pp. 1-4.

[19] Christodoulou C. A., Vita V., Ekonomou L., Chatzarakis G. E., Stathopulos I. A., "Application of Powell's optimization method to surge arrester circuit models' parameters," Energy, vol. 35, no. 8, pp. 3375-3380, 2010.

[20] E. Savary, S. Marinel, F. Gascoin, Y. Kinemuchi, J. Pansiot And R. Retoux, "Peculiar effects of microwave sintering on ZnO based varistors properties," Journal of Alloys and Compounds, vol. 509, no. 21, pp. 6163-6169, 2011.

[21] Jinliang He, A. Chenlu Cheng, and Jun Hu, "Electrical degradation of double-Schottky barrier in ZnO varistors," AIP Advances, vol. 6, 030701, 2016.

[22] Seyyedbarzegar, S. M., and Mirzaie, M., "Thermal balance diagram modelling of surge arrester for thermal stability analysis considering $\mathrm{ZnO}$ varistor degradation effect," IET Generation, Transmission \& Distribution, vol. 10, no. 7, pp. 1570-1581, 2016.

[23] Thipprasert, W., and Sritakaew, P., "Leakage Currents of Zinc Oxide Surge Arresters in 22 kV Distribution System Using Thermal Image Camera,” Journal of Power and Energy Engineering, vol. 2, no. 4, pp. 712-717, 2014.

[24] Wichet Thipprasert and Prakasit Sritakaew, "Leakage Currents of Zinc Oxide Surge Arresters in 22 kV Distribution System Using Thermal Image Camera," Journal of Power and Energy Engineering, vol. 2, no. 4, pp. 712-717, 2014.

[25] Rahisham abd rahman, "investigations of zno microvaristor for stress control on polymeric outdoor insulators," thesis Doctor School of Engineering, Cardiff University, Aug. 2012.

[26] Christodoulou, C. A, et al., "Measurement of the resistive leakage current in surge arresters under artificial rain test and impulse voltage subjection," IET Science, Measurement \& Technology, vol. 3, no. 3, pp. 256-262, 2009.

[27] Christodoulou C. A., Spanias C. A., "Study of the Electric Field around a Metal Oxide Surge Arrester: Measurement and Simulation,” High Voltage Engineering, vol. 39, no. 8, pp. 2014-2021, 2013.

[28] Abelhakim Bendakir, Abdelhafid Bayadi, Djalel Dib, A. Tahar Azar, "Analysis of electromagnetic field emitted by power line currents," International Journal of Intelligent Engineering Informatics, vol. 4, no. 2, pp. 188-203, 2016.

[29] Denz F., Gjonaj E., Weiland T., "Nonlinear Characterization and Simulation of Zinc-Oxide Surge Arresters," Scientific Computing in Electrical Engineering SCEE 2010, vol. 16, pp. 213-221, 2011.

[30] Soon-Man Yang, Bok-Hee Lee, and Seung-Kwon Paek, "Electrical Behaviors of ZnO Elements under Combined Direct and Alternating Voltages, Journal of Electrical Engineering \& Technology, vol. 4, no. 1, pp. 1-9, 2009.

[31] Y. Späck-Leigsnering, E. Gjonaj, H. De Gersem, T. Weiland, M. Gießel and V. Hinrichsen, "Investigation of Thermal Stability for a Station Class Surge Arrester," in IEEE Journal on Multiscale and Multiphysics Computational Techniques, vol. 1, pp. 120-128, 2016.

[32] Klaus Moritz, Gießel, "Elektrothermisches Verhalten von Hochspannungs-Metalloxid-Ableitern mit reduzierten Steuersystemen in Wechselspannungsnetzen," Genehmigte Dissertation, 2018.

\section{BIOGRAPHIES OF AUTHORS}

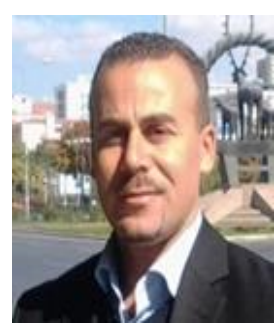

Abdelhakim Bendakir was born in Mila, Algeria. Received the Engineer degree in Electrical modeling of power systems from the University of Jijel, in 2004. Moreover, he got his Magister Degree, in electrical networks from the University of Jijel, in 2008. Since 2011, he became an Assistant Professor at Tebessa university. His research interests include High Voltage Equipment, Transient Overvoltages Analysis, Electromagnetic Fields, and Renewable Energy. 


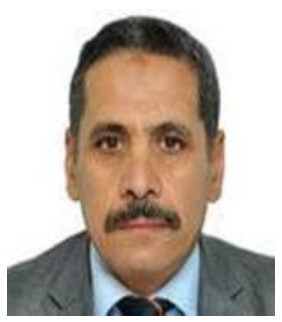

Abdelhafid Bayadi was born in Setif, Algeria. He joined Setif institute in 1998 as an Assistant Professor. He obtained then a Ph.D. degree in 2005. In the same year, he was appointed a Senior Lecturer and in 2010, a Professor in electrical engineering. His research interests are power system transients, high voltage engineering, and insulation technology. He has co-authored over 40 publications. He is a member of the Steering Committee in CNHT Conference.

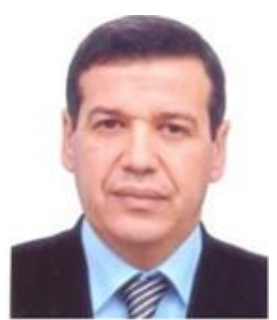

Djalel Dib is currently working as a Research Professor with the rank of Senior Lecturer in the Department of Electrical Engineering at the University of Tebessa in Algeria. He received his $\mathrm{PhD}$ diploma in Power Systems from University of Annaba in Algeria in 2007. He participated in several international conferences, and he has published several papers in various international journals. Currently, he is a senior research in Laboratory of Electrical Engineering in Tebessa LABGET and leading two projects approved and funded by the Algerian state, he is also designated as a reviewer in several journals. His research interests 'fieldsare the electric power networks, the power quality and the renewable energy. 